\title{
Predictive factors of response to mTOR inhibitors in neuroendocrine tumours
}

\author{
Maria Chiara Zatelli', Giuseppe Fanciulli ${ }^{2}$, Pasqualino Malandrino ${ }^{3}$, Valeria Ramundo ${ }^{4}$, \\ Antongiulio Faggiano ${ }^{5}$, and Annamaria Colao ${ }^{4}$ on behalf of NIKE Group
}

${ }^{1}$ Section of Endocrinology and Internal Medicine, Department of Medical Sciences, University of Ferrara, Via Aldo Moro 8, 44124 Cona - Ferrara, Italy

${ }^{2}$ Neuroendocrine Tumours Unit, Department of Clinical and Experimental Medicine, University of Sassari AOU Sassari, Sassari, Italy

${ }^{3}$ Endocrinology Unit, Garibaldi Nesima Medical Center, Catania, Italy

${ }^{4}$ Department of Clinical Medicine and Surgery, "Federico II" University of Naples, Naples, Italy

${ }^{5}$ Thyroid and Parathyroid Surgery Unit, Istituto Nazionale per lo studio e la cura dei tumori

"Fondazione G. Pascale" - IRCCS, Naples, Italy

(Details of the NIKE Group is given in the Acknowledgement section)

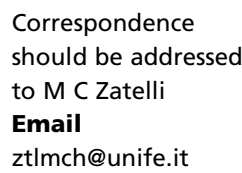

\begin{abstract}
Medical treatment of neuroendocrine tumours (NETs) has drawn a lot of attention due to the recent demonstration of efficacy of several drugs on progression-free survival, including somatostatin analogs, small tyrosine kinase inhibitors and mTOR inhibitors (or rapalogs). The latter are approved as therapeutic agents in advanced pancreatic NETs and have been demonstrated to be effective in different types of NETs, with variable efficacy due to the development of resistance to treatment. Early detection of patients that may benefit from rapalogs treatment is of paramount importance in order to select the better treatment and avoid ineffective and expensive treatments. Predictive markers for therapeutic response are under intensive investigation, aiming at a tailored patient management and more appropriate resource utilization. This review summarizes the available data on the tissue, circulating and imaging markers that are potentially predictive of rapalog efficacy in NETs.
\end{abstract}
Key Words
- mTOR inhibitors
- neuroendocrine tumours
- predictors
- response to treatment

\section{Introduction}

Neuroendocrine tumours (NETs) consist of a spectrum of malignancies that can arise from neuroendocrine cells throughout the body. Despite NETs having been considered rare for a long time, large epidemiological studies have reported that the observed incidence has increased from 1.09 to $5.25 / 100,000$ from 1973 to 2004 (Yao et al. 2008a). Therapeutic tools for NETs include surgery, somatostatin analogs (SSA), peptide receptor radionuclide therapy, interferon alfa, tyrosine kinase inhibitors, chemotherapy, as well as loco-regional treatments (such as radiofrequency ablation and selected transcatheter arterial chemoembolization) (Modlin et al. 2010a, Oberg et al. 2010, Frilling et al. 2012, Pavel et al. 2012). Mammalian target of rapamycin (mTOR) inhibitors are emerging among the new targeted therapies as powerful tools in NET medical therapy.

mTOR is a serine/threonine protein kinase found in two major complexes: mTORC1 and mTORC2. mTORC1 is sensitive to the inhibition by rapamycin and mainly controls the energy status of the cell. This occurs also by

Published by Bioscientifica Ltd. 
transducing PI3K/Akt-dependent growth factor signalling, such as insulin and IGF-1, and thus participating in the regulation of cell growth, survival and proliferation. mTORC2, which is rapamycin-insensitive, mainly influences the actin cytoskeleton, determining cell shape and modulating cell motility (Hay \& Sonenberg 2004, Wullschleger et al. 2006). Rapamycin and its analogs ('rapalogs') bind the FK506 binding protein (FKBP12) in the cytoplasm, which, in turn, binds and inactivates mTORC1 and related downstream signalling (Meric-Bernstam \& GonzalezAngulo 2009). Rapalogs have been shown to modulate cell proliferation, metabolism and angiogenesis in several in vitro models, including NETs. Zitzmann et al. (2007) showed that everolimus, a rapalog currently available for the medical therapy of NET of pancreatic origin (pNET) (Pavel 2013), dose-dependently reduces growth and causes apoptosis as well as arrest in the G0/G1 phase of the cell cycle in a human pNET cell line. This cell line, the BON1 cells, displays constitutive activation of the Akt/mTOR pathway due to an autocrine IGF-I loop (von Wichert et al. 2000). Zitzmann also provided evidence that selective mTORC1 inhibition by everolimus induces Akt signalling upregulation, a mechanism possibly responsible for rapalog resistance. Similar findings have also been shown by Grozinsky-Glasberg et al. (2008) in a rat insulinoma cell line, where everolimus was capable of inhibiting TSC2, mTOR and p70S6K but not Akt phosphorylation, with no additive effect when used in combination with the SSA octreotide. This drug was unable to enhance the antiproliferative effects of rapamycin in two NET cell lines: the BON1 cell line and a cell line derived from a human bronchial carcinoid, the NCI-H727 cells. In these settings, rapamycin stimulated Akt phosphorylation, an effect that octreotide failed to overcome, further indicating that the Akt activating loop may cause rapalog resistance (Moreno et al. 2008). However, the molecular determinants of rapalog resistance are still unclear, despite the extensive investigation of the mTOR pathway, where several alterations have been described in NETs (Missiaglia et al. 2010).

The main rapalogs employed in clinical trials involving NETs are represented by everolimus and temsirolimus (Marotta et al. 2013, Chan \& Kulke 2014). On the basis of the results of randomized placebo-controlled studies on patients with advanced pNETs, which showed improved progression-free survival (PFS; Yao et al 2008b, 2010), everolimus has been approved for the treatment of patients with advanced pNETs. In addition, the RADIANT-4 trial has recently shown that everolimus reduces the risk of progression and prolongs PFS in advanced, progressive, non-functioning NETs originating from the gastrointestinal tract and from the lungs (ESMO 2015, Yao et al. 2015; ClinicalTrials.gov ID: NCT01524783).

Despite promising results on tumour progression, everolimus shows a limited impact on tumour bulk, in keeping with the cytostatic rather than cytotoxic action of rapalogs. Indeed, everolimus efficacy in NETs may vary depending on the patient and on the development of rapalog resistance. Early detection of responder vs nonresponder patients would thus be crucial to avoid ineffective and expensive treatments, shifting to alternative therapies early after treatment initiation.

\section{Aim}

This review summarizes the available data on tissue, circulating and imaging markers of mTOR inhibitor efficacy in NETs that may help to identify patients who may benefit from treatment with mTOR inhibitors.

\section{Methodology}

Four of the authors ( $\mathrm{M} \mathrm{C} \mathrm{Z,} \mathrm{G} \mathrm{F,} \mathrm{P} \mathrm{M} \mathrm{and} \mathrm{V} \mathrm{R)}$ independently searched MEDLINE (PubMed database) to identify potentially relevant articles on the predictive factors of efficacy of mTOR inhibitors in NET treatment. The search was last updated October 30th, 2015. Only articles published in the English language were considered. The search strategy included the following terms: 'neuroendocrine tumour', 'neuroendocrine carcinoma', 'predictive', 'response', 'everolimus', 'temsirolimus' or 'rapamycin'. Additional studies were identified by reviewing the references of all selected articles. Different article types were considered and only Editorials and Letters were excluded.

Overall, 147 articles were identified and collected in a single file, which was sent to all authors. Potentially relevant factors for predicting the response to mTOR inhibitors were divided into three main topics: tissue markers, circulating markers and imaging. Articles were selected by screening the title and abstract to identify only those that dealt with at least one of these three topics. The selected abstracts were then further assessed for a full-text evaluation.

\section{Tissue markers}

An activated PI3K/AKT/mTOR pathway has been described in different NETs, including pancreatic,

Published by Bioscientifica Ltd 
gastrointestinal and lung tumours (Shida et al. 2010, Righi et al. 2010). Since an evident association between the expression levels of the PI3K/AKT/mTOR pathway and the survival of patients with NETs has been reported, it is reasonable to speculate that the analysis of this pathway may be useful to predict the clinical behaviour of NETs and possibly their response to rapalog treatment.

Tissue specimens allow a reliable assessment of both mutational status and expression levels of the mTOR pathway components through DNA/protein studies and immunohistochemistry (IHC) (Alì et al. 2011, Kasajima et al. 2011). Moreover, tissue analysis can be useful in the characterization of unresectable NETs undergoing bioptic procedures, which sometimes retrieve only small amounts of tumour tissue. In such cases, the sample may not be sufficient for an appropriate immunohistochemical characterization, but may be suitable for molecular studies, allowing to isolate somatic DNA, RNA or proteins.

DNA studies may then be performed, since they do not need huge amounts of tissue nor a demanding storage procedure. NET mutational profiles have been extensively investigated (Jiao et al. 2011, Oberg et al. 2013, Francis et al. 2013, Fernandez-Cuesta et al. 2014, Kidd et al. 2015a), leading to the observation that they are extremely variable depending on the site. Somatic mutations have also been intensively investigated to possibly predict sensitivity or resistance to mTOR inhibitors. Previous studies have shown that the presence of oncogenic variants of the phosphoinositide-3-kinase catalytic subunit (PIK3CA) and of Kirsten Rat Sarcoma Viral Oncogene Homolog (KRAS) may influence the response of breast cancer cells to everolimus. Mutations in the PI3K pathway components were found in human cell lines that respond to rapalogs in terms of antiproliferative effects (Di Nicolantonio et al. 2010). The PIK3CA gene, however, is rarely mutated in pNETs (Jiao et al. 2011) and PI3K-p85a subunit mutations as well as PI3K amplifications have not been reported in NETs, so far (Briest \& Grabowski 2014). Data on KRAS mutations in pNETs are also controversial: none of the 44 pNETs belonging to a Caucasian cohort was found to harbour KRAS somatic mutations (Gilbert et al. 2013), which were on the contrary reported in four out of 37 consecutive Chinese pNET patients (Yuan et al. 2014). In addition, KRAS somatic mutations have not been reported in Goblet cell NETs of the appendix (Dimmler et al. 2014), while Sahnane et al. (2015) identified KRAS mutations in 13 colorectal and two in gastric neuroendocrine carcinomas (NEC) among 53 cases of gastro-entero-pancreatic NEC. KRAS somatic oncogenic mutations characterize cancer patients who do not benefit from everolimus treatment, indicating that KRAS and PIK3CA mutations may represent useful biomarkers to predict the efficacy of mTOR inhibitors. Indeed, KRAS mutations have been reported to confer resistance to everolimus treatment, even in the presence of PI3K mutations. Di Nicolantonio et al. (2010) observed everolimus resistance in human cancer cells with both PIK3CA and KRAS mutations; sensitivity to everolimus was restored after genetically deleting KRAS mutations. Moreover, they confirmed this finding in clinical settings when evaluating the response to everolimus in metastatic cancer patients: lack of response to everolimus was associated with oncogenic KRAS mutations. Clinical studies reporting higher patient numbers are needed to better estimate the prevalence of KRAS somatic mutation in NETs and its role in predicting the response to the treatment with rapalogs.

Mutations in Phosphatase and Tensin Homolog (PTEN) gene, leading to a reduced protein expression, have also been reported to characterize the NET cell lines that are sensitive to the antiproliferative effects of rapalogs (Meric-Bernstam et al. 2012). Indeed, mTOR inhibitors can effectively control PTEN-deficient tumour growth in several models (Neshat et al. 2001, Shi et al. 2002, DeGraffenried et al. 2004, Steelman et al. 2008), but PTEN loss failed to predict sensitivity to everolimus in glioblastoma orthotopic xenografts. PTEN mutations, as well as altered PTEN expression, have also been reported in pNETs (Missiaglia et al. 2010), especially those showing an aggressive clinical behaviour, suggesting that PTEN may be useful as a predictive marker in pNET. This is supported by the observation that loss of PTEN is associated with a shorter time to progression in patients with NEC treated with temsirolimus (Duran et al. 2006).

Other genetic mutations have been evaluated as putative biomarkers to predict rapalog sensitivity. A single-nucleotide polymorphism (SNP) in the fibroblast growth factor receptor isoform 4 gene (FGFR4), causing a conversion of guanine to adenine at position 1.217 in exon 9 (FGFR4-G388R), has been reported to associate with a worse prognosis in several human cancers (Morimoto et al. 2003, Wang et al. 2004, Thussbas et al. 2006, da Costa Andrade et al. 2007, Sasaki et al. 2008, Falvella et al. 2009). Serra et al. (2012) showed that, in pNET patients, the FGFR4-G388R allele (assessed at germline level) associates with a tumour diameter $>2 \mathrm{~cm}$, local invasiveness, lymphovascular invasion, lymph node and liver metastases. In addition, BON1 xenografts (Evers et al. 1991), over-expressing FGFR4-R388, display a very aggressive behaviour in the animal model and a reduced responsiveness to everolimus. Similarly, pNET patients

Published by Bioscientifica Ltd. 
displaying at least one FGFR4-G388R allele show a statistically significant reduction in response to everolimus in vivo. On the other hand, a retrospective study recently reported that the presence of an FGFR4-G388R allele does not influence PFS, overall survival (OS) and mTOR pathway components expression in patients with NET of the small bowel or of the pancreas (Cros et al. 2015). The Authors concluded that FGFR4-G388R allele does not predict everolimus sensitivity in pNETs. Therefore, the role of the FGFR4-G388R allele as a predictive marker of pNET rapalog sensitivity is still very controversial. In conclusion, since NETs apparently display few relevant mutations, DNA profiling may not help in predicting therapeutic responsiveness. On the other hand, epigenetic approaches may be more relevant since most of the mutated genes are involved in chromatin remodelling (Pipinikas et al. 2015).

Protein studies may be more difficult due to the scant amount of tissue which is often available. Nevertheless, biopsies in patients with NETs have shown that baseline AKT activation not only characterizes an aggressive clinical course, but also associates with an increased PFS under treatment with everolimus and octreotide (openlabel phase II trial NCT00113360) (Ghayouri et al. 2010, Meric-Bernstam et al. 2012, Zitzmann et al. 2012). Similarly, it has been previously demonstrated that phosphorylated mTOR protein levels differentiate human bronchial carcinoids that are sensitive from those that are resistant to everolimus treatment in vitro. In addition, AKT/mTOR pathway signalling molecules in their active form (i.e. phosphorylated), such as basal mTOR, p70S6K, AKT and ERK1/2, are expressed at higher levels in human bronchial carcinoids responding to everolimus treatment in vitro, as compared to those resistant (Gagliano et al. 2013). Therefore, these markers may be useful to identify human NETs that may benefit from medical therapy with mTOR inhibitors. However, the potential predictive value of such markers has not been tested yet in other NETs, indicating the need for further validation studies to test the predictive value towards rapalog sensitivity of phosphorylated AKT, 4EBP1, S6K1 and S6 as well as of the presence of PTEN or PIK3CA mutations in NETs (Wander et al. 2011).

Several studies investigated the relationship between clinical outcome and IHC scores for mTOR signalling pathway proteins, but findings are discordant and only few studies analysed the efficacy of IHC in predicting the response to mTOR inhibitors in patients with NETs. In addition, the capability of these markers to predict survival is still very controversial (Zhou et al. 2011,
Qian et al. 2013, Ruza et al. 2014). The expression of the mTOR pathway components may be highly heterogeneous among different types of NETs, depending on both the primary site and the grading. Higher mTOR expression and activity have been found in foregut than in midgut NETs, also depending on the presence of metastases (Kasajima et al. 2011). The expression of phosphomTOR and its downstream targets has been reported to be significantly different between low-to-intermediate grade tumours (i.e. typical and atypical carcinoids) and high grade tumours (i.e. large cell neuroendocrine carcinomas and small cell lung cancers) (Righi et al. 2010). Moreover, a strong expression of phospho-mTOR was observed more frequently in poorly differentiated as compared to well differentiated gastroenteropancreatic NETs (Shida et al. 2010, Catena et al. 2011). Bollard et al. (2013) observed a strong expression of the two major mTOR effectors (phospho-p70S6K and phospho-4EBP1) in six human tissue samples of NECs. They also investigated the effect of everolimus in a xenograft model of two NET cell lines (STC-1 and GluTag cells) in nude mice and found that the tumours derived from these cell lines mimicked NEC behaviour in vivo. In addition, treatment of xenografted mice with everolimus caused a significant reduction in tumour volume, which correlated with mTOR signalling inhibition. Duran et al. (2006) evaluated mTOR pathway components by IHC in 13 paired biopsies (obtained before and after 2 weeks of temsirolimus therapy) in patients with advanced NEC. Higher baseline expression of phosphomTOR was predictive of tumour response. In addition, they found that after 2 weeks of treatment with temsirolimus an increased time to progression was associated with increased phospho-AKT and decreased phospho-mTOR expression. Spada et al. (2014) observed that among 36 patients with metastatic gastro-enteropancreatic NETs treated with everolimus $10 \mathrm{mg}$ once daily, patients with Ki-67 $\leq 20 \%$ (30/36) displayed a longer PFS when phospho-mTOR IHC score was positive as compared to those with negative phospho-mTOR IHC. These data suggest that mTOR pathway components IHC score in combination with $\mathrm{Ki}-67$ labelling index may predict the response to the treatment with mTOR inhibitors. On other clinical grounds, two trials reported similar benefit from everolimus treatment in both well and moderately differentiated NETs, regardless of the neuroendocrine differentiation grade (Pavel et al. 2011, Yao et al. 2011a).

Sensitivity to mTOR inhibitors is not always directly related to PI3K/AKT/mTOR signalling. Because of compensatory feedback loops and cross talk between the PI3K/AKT/mTOR cascade and other pathways

Published by Bioscientifica Ltd 
(Markman et al. 2010, Burris 2013), resistance to mTOR inhibitor drugs is not a rare event. This is confirmed by observations both in trials and in real-world clinical settings. For instance, the PI3K/AKT/mTOR pathway may be activated upstream by a mutated and constitutively activated RAS/MAPK pathway. Indeed, adaptive resistance to everolimus monotherapy has been observed in a genetically engineered mouse model of pNET, where a significant regression in tumour burden was documented by combining everolimus with erlotinib, which acts through the inhibition of the epithelial growth factor receptor. (Chiu et al. 2010). Further studies are required to confirm these findings. In addition, controversies may come from well-known limitations of IHC, such as the possibility of different methods of staining evaluation and threshold values for distinguishing between negative and positive samples. IHC analysis is often performed on tissues obtained at diagnosis; subsequently, patients are treated with one or more types of antineoplastic therapies and tumour biology may change, no longer correlating with the initial mTOR pathway status.

In summary, IHC analysis of NETs allows the identification of patients with hyperactivated PI3K/ AKT/mTOR pathway components, thus hypothetically leading to select which patient may benefit from treatment with mTOR inhibitors. However, the available evidence to support the utility of this evaluation for predicting the response to mTOR inhibitors is weak. Further studies with a better selection of patient cohorts (to reduce selection and measurement bias) and combined therapies targeting different signalling pathways (to overcome drug resistance) are warranted. At present, evaluating PI3K/AKT/mTOR pathway components by IHC is unlikely to achieve a satisfying and reliable predictive value (Delbaldo et al. 2011).

\section{Circulating markers}

In addition to tumour samples, putative markers to predict sensitivity to rapalogs could be evaluated in peripheral blood, ensuring that these agents are delivered to those patients that are most likely to respond. The role of bloodbased biomarkers has been recently addressed in a consensus review, which underlined the important limitations of monoanalyte biomarkers and the potential importance of circulating multianalyte biomarkers in predicting treatment efficacy (Oberg et al. 2015).

Chromogranin A ( CgA), a circulating peptide, is usually considered the most helpful marker in patients with NETs. Elevated CgA levels are known to associate with poor PFS and OS in NET patients (Modlin et al. 2010b, Lawrence et al. 2011). Neuron-specific enolase (NSE), on the contrary, has a scant clinical applicability, since it demonstrated low sensitivity and specificity as a NET biomarker (Baudin et al. 1998, Vinik et al. 2009). Yao et al. $(2011 b)$ provided information regarding the prognostic role of CgA and NSE in patients with advanced pNETs under treatment with everolimus in the RADIANT-1 (enrolling patients with low to intermediate grade advanced pNET) (Yao et al. 2010) and in the MDACC US-52 study at The University of Texas MD Anderson Cancer Center (enrolling patients with low to intermediate grade advanced carcinoid tumours and pNETs). The analysis of the biomarker pattern in patients under treatment with everolimus suggests that an early reduction in CgA or NSE level may predict a longer PFS in patients with pNET. Early modifications in CgA and NSE levels are therefore potentially important markers of response in pNET patients treated with everolimus, an issue that needs to be confirmed in prospective, randomized studies (Yao et al. 2011b).

Circulating tumours cells are detectable in patients with midgut NETs and with pNETs (Khan et al. 2011), where they could be considered a prognostic marker (Khan et al. 2013). Indeed, a recent study provides information as concerns the role of CTC count as predictive of response to treatment with several different approaches (including SSA, chemotherapy, peptide receptor radionuclide therapy, transarterial embolization, radiofrequency ablation, sunitinib, interferon alpha and surgery) that did not include rapalog treatment (Khan et al. 2015). Further research is needed to fully exploit the potential predictive role of CTCs in the context of NET medical therapy by means of rapalogs.

The expression profile of microRNAs (miRNAs), small noncoding RNAs involved in gene expression regulation, has been reported to be quite specific in pNETs (Roldo et al. 2006), but data on serum miRNAs as potential biomarkers of clinical behaviour as well as of response to medical treatment are not available, to date (Modlin et al. 2014a).

It has been recently suggested that Multianalyte Algorithmic tests (MAAAs) may perform much better as compared to monoanalyte markers, taking advantage of the simultaneous evaluation of several markers. To test this hypothesis, Modlin et al. (2013) developed a gene biomarker assay that includes several genes selected on the basis of the results of microarray data and by means of a computational strategy. This test has been applied to identify candidate marker genes in peripheral circulation

Published by Bioscientifica Ltd. 
of patients with NETs with high performance (Modlin et al. 2014b) independent of age, gender, ethnicity, fasting or proton pump inhibitor treatment and identified affected patients with high sensitivity and specificity (Modlin et al. 2014c). Along the same line, Kidd et al. $(2015 b)$, matched the results of the evaluation of the 51 circulating transcripts identified by MAAA with the analysis of tumour tissue transcripts, divided into different gene clusters, and applied an MAAA/cluster integrated algorithm. The latter was capable of accurately separate NETs with progressive disease from those displaying stable disease after different lines of therapy, predicting the disease status by means of a disease activity NET score, the NETest. The NETest appears to be a very promising tool not only for the diagnosis but also for the follow-up of NET patients, although to date no information is available concerning a predictive role for the NETest as concerns rapalog sensitivity.

\section{Imaging}

Tumour measurement by computed tomography (CT) using the Response Evaluation Criteria in Solid Tumours (RECIST) (Therasse et al. 2000, Therasse et al. 2006) has been considered for a long time the gold standard to evaluate the effect of antineoplastic drugs. However, the effect of cytostatic drugs, whose antineoplastic action may not be immediately followed by a reduction in tumour size, can represent a limit in the use of RECIST criteria (Benjamin et al. 2007). Positron Emission Tomography (PET) is emerging as a powerful tool, capable of overtaking CT measurement limits, offering additional information useful for treatment monitoring (Eisenhauer et al. 2009) and predicting the response to chemotherapy at an earlier stage (Jensen et al. 2010).

\section{Studies in animal models}

18F-fluorodeoxyglucose (FDG) PET is the most widely employed PET in oncology. FDG uptake mirrors cell glycolytic activity and may correlate, in some tumours, with early treatment responses (Weber \& Wieder 2006).

18F-fluorothymidine (FLT) PET, on the other hand, reflects proliferation (Shields et al. 1998). FLT is a thymidine analog, similar to the nucleotide usually incorporated during DNA synthesis (Kong et al. 1992). In humans, 18-FLT PET has recently shown its usefulness for predicting the response to carbon ion radiotherapy in subjects with melanoma (Inubushi et al. 2013). Johnbeck et al. (2014) investigated in animal models (mice) the ability of 18F-FDG PET and 18F-FLT PET to predict tumour response to everolimus. Mice were inoculated with a human NET cell line (lung carcinoid) and tumours were allowed to grow for 2 weeks. Then, the experimental animals underwent $\mathrm{CT}$ for tumour size measurements, and scanning with 18F-FDG and 18F-FLT PET (baseline). Mice were then treated with either everolimus $(5 \mathrm{mg} / \mathrm{kg}$ daily, subcutaneously) or with placebo for 10 days. CT as well as 18-FDG and 18-FLT PET for measurements of tumour size were then performed. The study showed that early 18F-FDG uptake (day 3) significantly correlated with tumour diameter at a later time point (day 10). Similarly, early 18F-FLT uptake (day 1) correlated with tumour growth at day 7, and 18F-FLT uptake at day 3 correlated with tumour growth at later time points (day 7 and 10). The authors conclude that early 18F-FLT uptake may predict later tumour growth and propose that 18F-FLT PET uptake could potentially be employed as an imaging biomarker for tailoring NET therapy. Moreover, 18F-FDG may represent a possible alternative in subjects with FLT-negative NETs. However, as outlined by the authors, the study was performed by using a single lung NET cell line and cannot demonstrate that early prediction of everolimus effect on tumour growth by PET imaging can hold for all NETs.

\section{Studies in humans}

Angiogenesis is a well-known hallmark of tumour growth (Hanahan \& Weinberg 2011). Vascular endothelial growth factor A (VEGF-A), in particular, plays a pivotal role in angiogenesis. The effect of everolimus on the reduction of VEGF-A production by tumour cells (Huynh et al. 2009) could potentially offer an early detection of responders vs non-responders. A PET method obtained by coupling the anti VEGF-A antibody bevacizumab to a radionuclide (89Zr-bevacizumab) has been shown to detect human neoplastic cells (Nagengast et al. 2007). van Asselt et al. (2014) investigated the performance of 89Zr-bevacizumab PET to predict tumour response to everolimus in patients showing progression of well-differentiated NETs. Fourteen patients underwent 89Zr-bevacizumab PET scanning before everolimus treatment, and then 2 and 12 weeks after treatment initiation. Ten out 14 patients showed positive 89Zr-bevacizumab PET scan findings. In this subset of patients, the Authors observed that the tumour Maximum Standardized Uptake Value (SUVmax) decreased in seven patients while it increased in three. Interestingly, after 6 months of therapy, the sum of target lesion diameters (measured by CT) showed a correlation

Published by Bioscientifica Ltd. 
with SUV max at 2 and 12 weeks (compared to SUV max at baseline). The authors concluded that sequential $89 \mathrm{Zr}$ bevacizumab PET scan might be employed to predict early the effects of everolimus. However, none of the 14 patients (including four 89Zr-bevacizumab PET negative scan patients) experienced progressive disease after 6 months of everolimus treatment. Thus, patients cannot be excluded from everolimus treatment on the basis of a negative 89Zr-bevacizumab PET scan

\section{Conclusions}

Multiple putative predictors of response to mTOR inhibitors have been proposed (Table 1), but the attempts to standardize these biomarkers have been mostly unsuccessful, possibly because PI3K/mTOR pathway complexity includes several feedback loops that may result in unpredictable effects. In addition, standardization of IHC and molecular techniques is very challenging, and genomic as well as epigenetic methods are promising but need accurate validation for clinical applications. Imaging, such as 18F-FLT or 18F-FDG PET, may represent a more attractive and clinically useful means to predict therapeutic responses to rapalogs, but validation studies on greater patient numbers are needed. Circulating markers are easier to assess, but reproducibility has not been strongly documented. Nevertheless, CgA and NSE levels may be assessed in NET patients undergoing rapalog therapy, until more powerful indicators will be identified. Indeed, single biomarkers are unlikely to achieve the goal to correctly predict NET responsiveness to rapalogs. On the other hand, new multimodal approaches, such as MAAA, may be more successful, also because they are based on easily accessible patient material, i.e. blood (associated or not to the corresponding tumour sample). The evaluation of the disease activity NET score at baseline may help in patient follow-up, and future studies will test the potential of the NETest to predict NET response to rapalogs.

In conclusion, the field of research for reliable predictive markers of response to rapalogs in NETs remains wide open, with the future perspective to identify basic and clinical predictors possibly useful to prospectively select patients who may benefit from rapalog treatment.

Table 1 Markers evaluated as predictive of response to mTOR inhibitors in NETs.

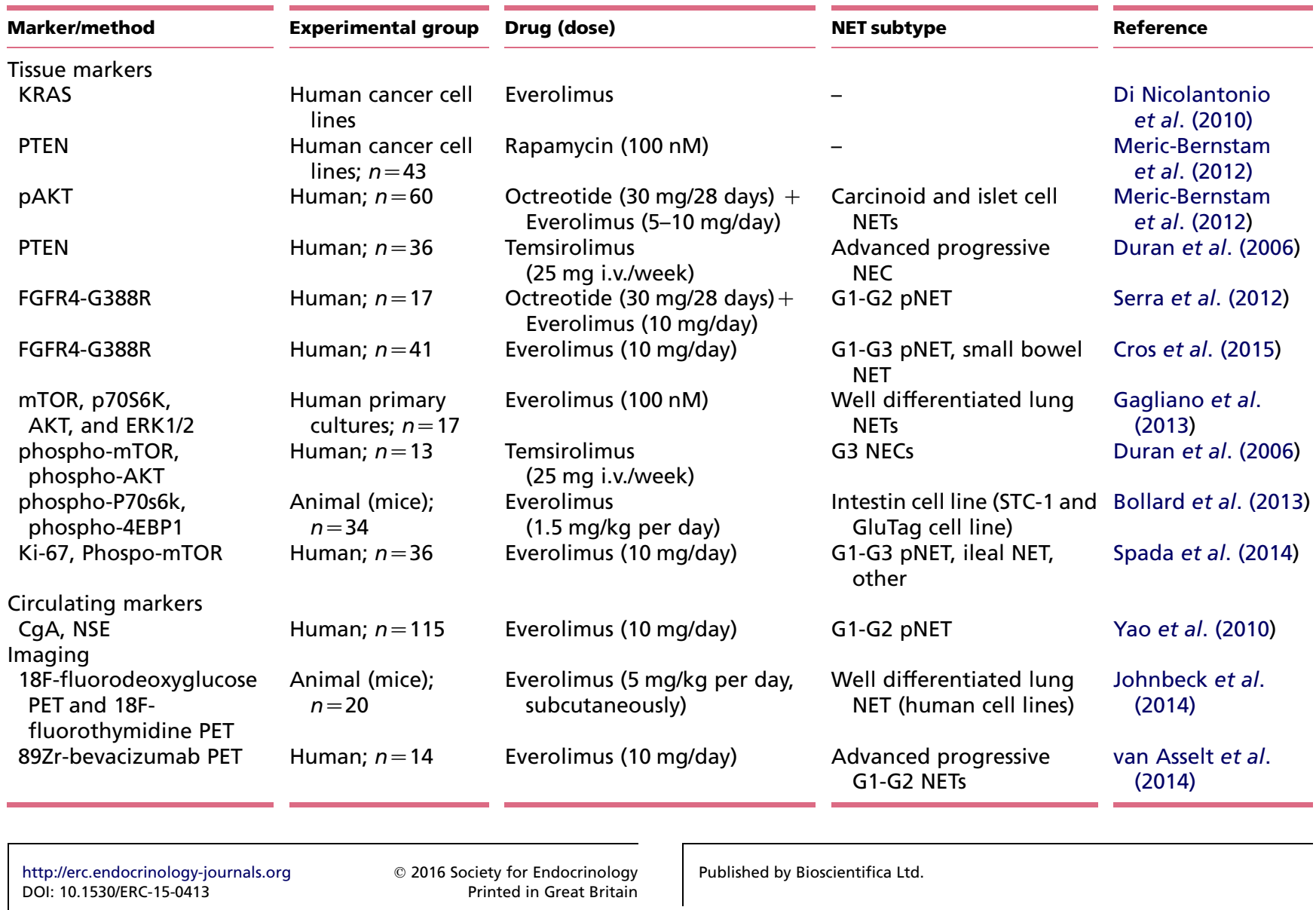




\section{Declaration of interest}

The authors declare that there is no conflict of interest that could be perceived as prejudicing the impartiality of this review.

\section{Funding}

M C Zatelli has received consultant fees from Novartis and Genzyme. This work was supported by grants from the Italian Ministry of Education, Research and University (FIRB RBAP11884 M, RBAP1153LS); Fondazione Cassa di Risparmio di Ferrara and Associazione Italiana per la Ricerca sul Cancro (AIRC) in collaboration with 'Laboratorio in rete del Tecnopolo Tecnologie delle terapie avanzate' (LTTA) of the University of Ferrara. This review is part of the 'NIKE' project (Neuroendocrine tumors Innovation Knowledge and Education) led by Prof Annamaria Colao, which aims at increasing the knowledge on NETs.

\section{Acknowledgements}

We would like to acknowledge all the Collaborators of this project: Manuela Albertelli, Emanuela Arvat, Roberto Baldelli, Alfredo Berruti, Antonio Bianchi, Lisa Bodei, Gerardo Botti, Francesco Corcione, Maria Vittoria Daví, Gianfranco Delle Fave, Laura De Marinis, Gaetano De Rosa, Antonella Di Sarno, Alessandra Dicitore, Nicola Fazio, Piero Ferolla, Diego Ferone, Angelina Filice, Marco Gallo, Carla Giordano, Dario Giuffrida, Valentina Guarnotta, Andrea Lania, Secondo Lastoria, Francesco Logoluso, Paola Loli, Marco Manzoni, Massimo Marchetti, Chiara Martini, Erika Messina, Roberta Modica, Cecilia Motta, Mauro Papotti, Stefano Partelli, Giovanni Persico, Anna Pia, Alessandro Piovesan, Genoveffa Pizza, Alfredo Pontecorvi, Paola Razzore, Francesca Rota, Francesco Scavuzzo, Concetta Sciammarella, Giovanni Vitale.

\section{References}

Alì G, Boldrini L, Capodanno A, Pelliccioni S, Servadio A, Crisman G, Picchi A, Davini F, Mussi A \& Fontanini G 2011 Expression of p-AKT and p-mTOR in a large series of bronchopulmonary neuroendocrine tumors. Experimental and Therapeutic Medicine 2 787-792. (doi:10.3892/ etm.2011.291)

van Asselt SJ, Oosting SF, Brouwers AH, Bongaerts AH, de Jong JR, Lub-de Hooge MN, Oude Munnink TH, Fiebrich HB, Sluiter WJ, Links TP et al. 2014 Everolimus reduces 89Zr-Bevacizumab tumor uptake in patients with neuroendocrine tumors. Journal of Nuclear Medicine 55 1087-1092. (doi:10.2967/jnumed.113.129056)

Baudin E, Gigliotti A, Ducreux M, Ropers J, Comoy E, Sabourin JC, Bidart JM, Cailleux AF, Bonacci R, Ruffié P et al. 1998 Neuron-specific enolase and chromogranin A as markers of neuroendocrine tumours. British Journal of Cancer 78 1102-1107. (doi:10.1038/bjc.1998.635)

Benjamin RS, Choi H, Macapinlac HA, Burgess MA, Patel SR, Chen LL, Podoloff DA \& Charnsangavej C 2007 We should desist using RECIST, at least in GIST. Journal of Clinical Oncology 25 1760-1764. (doi:10.1200/ JCO.2006.07.3411)

Bollard J, Couderc C, Blanc M, Poncet G, Lepinasse F, Hervieu V, Gouysse G, Ferraro-Peyret C, Benslama N, Walter T et al. 2013 Antitumor effect of everolimus in preclinical models of high-grade gastroenteropancreatic neuroendocrine carcinomas. Neuroendocrinology 97 331-340. (doi:10.1159/000347063)

Briest F \& Grabowski P 2014 3PI3K-AKT-mTOR-signaling and beyond: the complex network in gastroenteropancreatic neuroendocrine neoplasms. Theranostics 4 336-365. (doi:10.7150/thno.7851)
Burris HA III 2013 Overcoming acquired resistance to anticancer therapy: focus on the PI3K/AKT/mTOR pathway. Cancer Chemotherapy and Pharmacology 71 829-842. (doi:10.1007/s00280-012-2043-3)

Catena L, Bajetta E, Milione M, Ducceschi M, Valente M, Dominoni F \& Colonna V 2011 Mammalian target of rapamycin expression in poorly differentiated endocrine carcinoma: clinical and therapeutic future challenges. Target Oncology 6 65-68. (doi:10.1007/s11523-0110171-z)

Chan J \& Kulke M 2014 Targeting the mTOR signaling pathway in neuroendocrine tumors. Current Treatment Options in Oncology 15 365-379. (doi:10.1007/s11864-014-0294-4)

Chiu CW, Nozawa H \& Hanahan D 2010 Survival benefit with proapoptotic molecular and pathologic responses from dual targeting of mammalian target of rapamycin and epidermal growth factor receptor in a preclinical model of pancreatic neuroendocrine carcinogenesis. Journal of Clinical Oncology 28 4425-4433. (doi:10.1200/JCO.2010. 28.0198)

Cros J, Moati E, Raffenne J, Hentic O, Svrcek M, de Mestier L, Sbidian E, Guedj N, Bedossa P, Paradis V et al. 2015 Gly388Arg FGFR4 Polymorphism is not predictive of Everolimus efficacy in welldifferentiated digestive Neuroendocrine Tumors. Neuroendocrinology [in press]. (doi:10.1159/000440724)

da Costa Andrade V Jr, Parise O, Hors CP, de Melo Martins PC, Silva AP \& Garicochea B 2007 The fibroblast growth factor receptor 4 (FGFR4) Arg388 allele correlates with survival in head and neck squamous cell carcinoma. Experimental and Molecular Pathology 82 53-57. (doi:10.1016/j.yexmp.2006.05.003)

DeGraffenried LA, Fulcher L, Friedrichs WE, Grünwald V, Ray RB \& Hidalgo M 2004 Reduced PTEN expression in breast cancer cells confers susceptibility to inhibitors of the PI3 kinase/Akt pathway. Annals of Oncology 15 1510-1516. (doi:10.1093/annonc/mdh388)

Delbaldo C, Albert S, Dreyer C, Sablin MP, Serova M, Raymond E \& Faivre S 2011 Predictive biomarkers for the activity of mammalian target of rapamycin (mTOR) inhibitors. Target Oncology 6 119-124. (doi:10.1007/s11523-011-0177-6)

Di Nicolantonio F, Arena S, Tabernero J, Grosso S, Molinari F, Macarulla T, Russo M, Cancelliere C, Zecchin D, Mazzucchelli L et al. 2010 Deregulation of the PI3K and KRAS signaling pathways in human cancer cells determines their response to everolimus. Journal of Clinical Investigation 120 2858-2866. (doi:10.1172/JCI37539)

Dimmler A, Geddert H \& Faller G 2014 EGFR, KRAS, BRAF-mutations and microsatellite instability are absent in goblet cell carcinoids of the appendix. Pathology - Research and Practice 210 274-278. (doi:10.1016/ j.prp.2014.01.002)

Duran I, Kortmansky J, Singh D, Hirte H, Kocha W, Goss G, Le L, Oza A, Nicklee T, Ho J et al. 2006 A phase II clinical and pharmacodynamic study of temsirolimus in advanced neuroendocrine carcinomas. British Journal of Cancer 95 1148-1154. (doi:10.1038/sj.bjc.6603419)

Eisenhauer EA, Therasse P, Bogaerts J, Schwartz LH, Sargent D, Ford R, Dancey J, Arbuck S, Gwyther S, Mooney M et al. 2009 New response evaluation criteria in solid tumours: revised RECIST guideline (version 1.1). European Journal of Cancer 45 228-247. (doi:10.1016/j.ejca.2008. 10.026)

ESMO 2015 Results from the RADIANT-4 trial may guide treatment of patients with advanced, progressive, non-functional lung/gastrointestinal neuroendocrine tumours. In ESMO @ ECC 2015: ProgressionFree Survival Prolonged with Everolimus in Patients with Advanced Lung/Gastrointestinal Neuroendocrine Tumours. Vienna, Austria: ESMO (available at: http://www.esmo.org/Conferences/Past-Conferences/ European-Cancer-Congress-2015/News/Progression-Free-SurvivalProlonged-with-Everolimus-in-Patients-with-Advanced-LungGastrointestinal-Neuroendocrine-Tumours)

Evers BM, Townsend CM Jr, Upp JR, Allen E, Hurlbut SC, Kim SW, Rajaraman S, Singh P, Reubi JC \& Thompson JC 1991 Establishment and characterization of a human carcinoid in nude mice and effect of various agents on tumor growth. Gastroenterology 101 303-311. 
Falvella FS, Frullanti E, Galvan A, Spinola M, Noci S, De Cecco L, Nosotti M, Santambrogio L, Incarbone M, Alloisio M et al. 2009 FGFR4 Gly388Arg polymorphism may affect the clinical stage of patients with lung cancer by modulating the transcriptional profile of normal lung. International Journal of Cancer 124 2880-2885. (doi:10.1002/ijc.24302)

Fernandez-Cuesta L, Peifer M, Lu X, Sun R, Ozretić L, Seidel D, Zander T, Leenders F, George J, Müller C et al. 2014 Frequent mutations in chromatin-remodelling genes in pulmonary carcinoids. Nature Communications 5 3518. (doi:10.1038/ncomms4518)

Francis JM, Kiezun A, Ramos AH, Serra S, Pedamallu CS, Qian ZR, Banck MS, Kanwar R, Kulkarni AA, Karpathakis A et al. 2013 Somatic mutation of CDKN1B in small intestine neuroendocrine tumors. Nature Genetics $\mathbf{4 5}$ 1483-1486. (doi:10.1038/ng.2821)

Frilling A, Akerström G, Falconi M, Pavel M, Ramos J, Kidd M \& Modlin IM 2012 Neuroendocrine tumor disease: an evolving landscape. EndocrineRelated Cancer 19 R163-R185. (doi:10.1530/ERC-12-0024)

Gagliano T, Bellio M, Gentilin E, Molè D, Tagliati F, Schiavon M, Cavallesco NG, Andriolo LG, Ambrosio MR, Rea F et al. 2013 mTOR, p70S6K, AKT, and ERK1/2 levels predict sensitivity to mTOR and PI3K/mTOR inhibitors in human bronchial carcinoids. Endocrine-Related Cancer 20 463-475. (doi:10.1530/ERC-13-0042)

Ghayouri M, Boulware D, Nasir A, Strosberg J, Kvols L \& Coppola D 2010 Activation of the serine/theronine protein kinase Akt in enteropancreatic neuroendocrine tumors. Anticancer Research 30 5063-5067.

Gilbert JA, Adhikari LJ, Lloyd RV, Halfdanarson TR, Muders MH \& Ames MM 2013 Molecular markers for novel therapeutic strategies in pancreatic endocrine tumors. Pancreas 42 411-421. (doi:10.1097/MPA. Ob013e31826cb243)

Grozinsky-Glasberg S, Franchi G, Teng M, Leontiou CA, Ribeiro de Oliveira A Jr, Dalino P, Salahuddin N, Korbonits M \& Grossman AB 2008 Octreotide and the mTOR inhibitor RAD001 (everolimus) block proliferation and interact with the Akt-mTOR-p70S6K pathway in a neuro-endocrine tumour cell line. Neuroendocrinology 87 168-181. (doi:10.1159/000111501)

Hanahan D \& Weinberg RA 2011 Hallmarks of cancer: the next generation. Cell 144 646-674. (doi:10.1016/j.cell.2011.02.013)

Hay N \& Sonenberg N 2004 Upstream and downstream of mTOR. Genes and Development 18 1926-1945. (doi:10.1101/gad.1212704)

Huynh H, Chow KH, Soo KC, Toh HC, Choo SP, Foo KF, Poon D, Ngo VC \& Tran E 2009 RAD001 (everolimus) inhibits tumour growth in xenograft models of human hepatocellular carcinoma. Journal of Cellular and Molecular Medicine 13 1371-1380. (doi:10.1111/j.1582-4934.2008. 00364.x)

Inubushi M, Saga T, Koizumi M, Takagi R, Hasegawa A, Koto M, Wakatuki M, Morikawa T, Yoshikawa K, Tanimoto Ket al. 2013 Predictive value of $3^{\prime}$-deoxy-3'-[18F]fluorothymidine positron emission tomography/ computed tomography for outcome of carbon ion radiotherapy in patients with head and neck mucosal malignant melanoma. Annals of Nuclear Medicine 27 1-10. (doi:10.1007/s12149-012-0652-x)

Jensen MM, Erichsen KD, Björkling F, Madsen J, Jensen PB, Højgaard L, Sehested M \& Kjær A 2010 Early detection of response to experimental chemotherapeutic Top216 with [18F]FLT and [18F]FDG PET in human ovary cancer xenografts in mice. PLoS One 5 e12965-2866. (doi:10.1371/journal.pone.0012965)

Jiao Y, Shi C, Edil BH, de Wilde RF, Klimstra DS, Maitra A, Schulick RD, Tang LH, Wolfgang CL, Choti MA et al. 2011 DAXX/ATRX, MEN1, and mTOR pathway genes are frequently altered in pancreatic neuroendocrine tumors. Science 331 1199-1203. (doi:10.1126/science.1200609)

Johnbeck CB, Munk Jensen M, Haagen Nielsen C, Fisker Hag AM, Knigge U \& Kjaer A 2014 18F-FDG and 18F-FLT-PET imaging for monitoring everolimus effect on tumor-growth in neuroendocrine tumors: studies in human tumor xenografts in mice. PLoS One 9 e91387-1926. (doi:10.1371/journal.pone.0091387)

Kasajima A, Pavel M, Darb-Esfahani S, Noske A, Stenzinger A, Sasano H, Dietel M, Denkert C, Röcken C, Wiedenmann B et al. 2011 mTOR expression and activity patterns in gastroenteropancreatic neuroendocrine tumours. Endocrine-Related Cancer 18 181-192. (doi:10.1677/ERC-10-0126)

Khan MS, Tsigani T, Rashid M, Rabouhans JS, Yu D, Luong TV, Caplin M \& Meyer T 2011 Circulating tumor cells and EpCAM expression in neuroendocrine tumors. Clinical Cancer Research 17 337-345. (doi:10.1158/1078-0432.CCR-10-1776)

Khan MS, Kirkwood A, Tsigani T, GarciaHernandez J, Hartley JA, Caplin ME \& Meyer T 2013 Circulating tumor cells as prognostic markers in neuroendocrine tumors. Journal of Clinical Oncology 31 365-372. (doi:10.1200/JCO.2012.44.2905)

Khan MS, Kirkwood AA, Tsigani T, Lowe H, Goldstein R, Hartley JA, Caplin ME \& Meyer T 2016 Early changes in circulating tumor cells are associated with response and survival following treatment of metastatic neuroendocrine neoplasms. Clinical Cancer Research 22 79-85. (doi:10.1158/1078-0432.CCR-15-1008)

Kidd M, Modlin IM, Bodei L \& Drozdov I 2015a Decoding the molecular and mutational ambiguities of gastroenteropancreatic neuroendocrine neoplasm pathobiology. Cellular and Molecular Gastroenterology and Hepatology 1 131-153. (doi:10.1016/j.jcmgh.2014.12.008)

Kidd M, Drozdov I \& Modlin I 2015b Blood and tissue neuroendocrine tumor gene cluster analysis correlate, define hallmarks and predict disease status. Endocrine-Related Cancer 22 561-575. (doi:10.1530/ERC15-0092)

Kong XB, Zhu QY, Vidal PM, Watanabe KA, Polsky B, Armstrong D, Ostrander M, Lang SA Jr, Muchmore E \& Chou TC 1992 Comparisons of anti-human immunodeficiency virus activities, cellular transport, and plasma and intracellular pharmacokinetics of $3^{\prime}$-fluoro-3'-deoxythymidine and $3^{\prime}$-azido-3'-deoxythymidine. Antimicrobial Agents and Chemotherapy 36 808-818. (doi:10.1128/AAC.36.4.808)

Lawrence B, Gustafsson BI, Kidd M, Pavel M, Svejda B \& Modlin IM 2011 The clinical relevance of chromogranin a as a biomarker for gastroenteropancreatic neuroendocrine tumors. Endocrinology Metabolism Clinics of North America 40 111-134. (doi:10.1016/j.ecl. 2010.12.001)

Marotta V, Franzese MD, Del Prete M, Chiofalo MG, Ramundo V, Esposito R, Marciello F, Pezzullo L, Carratù A, Vitale M et al. 2013 Targeted therapy with kinase inhibitors in aggressive endocrine tumors. Expert Opinion on Pharmacotherapy 14 1187-1203. (doi:10.1517/14656566.2013.796931)

Markman B, Dienstmann R \& Tabernero J 2010 Targeting the $\mathrm{PI} 3 \mathrm{~K} / \mathrm{Akt} / \mathrm{mTOR}$ pathway - beyond rapalogs. Oncotarget 1 530-543. (doi:10.18632/oncotarget.188)

Meric-Bernstam F \& Gonzalez-Angulo AM 2009 Targeting the mTOR signaling network for cancer therapy. Journal of Clinical Oncology 27 2278-2287. (doi:10.1200/JCO.2008.20.0766)

Meric-Bernstam F, Akcakanat A, Chen H, Do K, Sangai T, Adkins F, Gonzalez-Angulo AM, Rashid A, Crosby K, Dong M et al. 2012 PIK3CA/PTEN mutations and Akt activation as markers of sensitivity to allosteric mTOR inhibitors. Clinical Cancer Research 18 1777-1789. (doi:10.1158/1078-0432.CCR-11-2123)

Missiaglia E, Dalai I, Barbi S, Beghelli S, Falconi M, della Peruta M, Piemonti L, Capurso G, Di Florio A, delle Fave G et al. 2010 Pancreatic endocrine tumors: expression profiling evidences a role for AKT-mTOR pathway. Journal of Clinical Oncology 28 245-255. (doi:10.1200/JCO. 2008.21.5988)

Modlin IM, Moss SF, Oberg K, Padbury R, Hicks RJ, Gustafsson BI, Wright NA \& Kidd M $2010 a$ Gastrointestinal neuroendocrine (carcinoid) tumours: current diagnosis and management. Medical Journal of Australia 193 46-52.

Modlin IM, Gustafsson BI, Moss SF, Pavel M, Tsolakis AV \& Kidd M $2010 b$ Chromogranin A biological function and clinical utility in neuroendocrine tumor disease. Annals of Surgical Oncology 17 2427-2443. (doi:10.1245/s10434-010-1006-3)

Modlin I, Drozdov I \& Kidd M 2013 The identification of gut neuroendocrine tumor disease by multiple synchronous transcript analysis in blood. PLoS One $\mathbf{8}$ e63364. (doi:10.1371/journal.pone. 0063364) 
Modlin I, Oberg K, Taylor A, Drozdov I, Bodei L \& Kidd M $2014 a$ Neuroendocrine tumor biomarkers: current status and perspectives. Neuroendocrinology 100 265-277. (doi:10.1159/000368363)

Modlin I, Drozdov I, Alaimo D, Callahan S, Teixeira N, Bodei L \& Kidd M $2014 b$ A multianalyte PCR blood test outperforms single analyte ELISAs for neuroendocrine tumor detection. Endocrine-Related Cancer 21 615-628. (doi:10.1530/ERC-14-0190)

Modlin I, Drozdov I \& Kidd M 2014c Gut neuroendocrine tumor blood qPCR fingerprint assay: characteristics and reproducibility. Clinical Chemistry and Laboratory Medicine 52 419-429. (doi:10.1515/cclm2013-0496)

Moreno A, Akcakanat A, Munsell MF, Soni A, Yao JC \& Meric-Bernstam F 2008 Antitumor activity of rapamycin and octreotide as single agents or in combination in neuroendocrine tumors. Endocrine-Related Cancer 15 257-266. (doi:10.1677/ERC-07-0202)

Morimoto Y, Ozaki T, Ouchida M, Umehara N, Ohata N, Yoshida A, Shimizu K \& Inoue H 2003 Single nucleotide polymorphism in fibroblast growth factor receptor 4 at codon 388 is associated with prognosis in high-grade soft tissue sarcoma. Cancer 98 2245-2250. (doi:10.1002/cncr.11778)

Nagengast WB, de Vries EG, Hospers GA, Mulder NH, de Jong JR, Hollema H, Brouwers AH, van Dongen GA, Perk LR \& Lub-de Hooge MN 2007 In vivo VEGF imaging with radiolabeled bevacizumab in a human ovarian tumor xenograft. Journal of Nuclear Medicine 48 1313-1319. (doi:10.2967/jnumed.107.041301)

Neshat MS, Mellinghoff IK, Tran C, Stiles B, Thomas G, Petersen R, Frost P, Gibbons JJ, Wu H \& Sawyers C 2001 Enhanced sensitivity of PTENdeficient tumors to inhibition of FRAP/mTOR. Proc Natl Acad Sci USA 98 10314-10319. (doi:10.1073/pnas.171076798)

Oberg K, Akerström G, Rindi G, Jelic S \& ESMO Guidelines Working Group 2010 Neuroendocrine gastroenteropancreatic tumours: ESMO Clinical Practice Guidelines for diagnosis, treatment and follow-up. Annals of Oncology 21 (Suppl 5) 223-227. (doi:10.1093/annonc/mdq192)

Oberg K, Casanovas O, Castaño JP, Chung D, Delle Fave G, Denèfle P, Harris P, Khan MS, Kulke MH, Scarpa A et al. 2013 Molecular pathogenesis of neuroendocrine tumors: implications for current and future therapeutic approaches. Clinical Cancer Research 19 2842-2849. (doi:10.1158/1078-0432.CCR-12-3458)

Oberg K, Modlin IM, De Herder W, Pavel M, Klimstra D, Frilling A, Metz DC, Heaney A, Kwekkeboom D, Strosberg J et al. 2015 Consensus on biomarkers for neuroendocrine tumour disease. Lancet Oncology 16 e435-e446. (doi:10.1016/S1470-2045(15)00186-2)

Pavel M 2013 Translation of molecular pathways into clinical trials of neuroendocrine tumors. Neuroendocrinology 97 99-112. (doi:10.1159/ 000336089)

Pavel ME, Hainsworth JD, Baudin E, Peeters M, Hörsch D, Winkler RE, Klimovsky J, Lebwohl D, Jehl V, Wolin EM, RADIANT-2 Study Group et al. 2011 Everolimus plus octreotide long-acting repeatable for the treatment of advanced neuroendocrine tumours associated with carcinoid syndrome (RADIANT-2): a randomised, placebo-controlled, phase 3 study. Lancet 378 2005-2012. (doi:10.1016/S01406736(11)61742-X)

Pavel M, Baudin E, Couvelard A, Krenning E, Öberg K, Steinmüller T, Anlauf M, Wiedenmann B, Salazar R \& Barcelona Consensus Conference Participants 2012 ENETS Consensus Guidelines for the management of patients with liver and other distant metastases from neuroendocrine neoplasms of foregut, midgut, hindgut, and unknown primary. Neuroendocrinology 95 157-176. (doi:10.1159/000335597)

Pipinikas CP, Dibra H, Karpathakis A, Feber A, Novelli M, Oukrif D, Fusai G, Valente R, Caplin M, Meyer T et al. 2015 Epigenetic dysregulation and poorer prognosis in DAXX-deficient pancreatic neuroendocrine tumours. Endocrine-Related Cancer 22 L13-L18. (doi:10.1530/ ERC-15-0108)

Qian ZR, Ter-Minassian M, Chan JA, Imamura Y, Hooshmand SM, Kuchiba A, Morikawa T, Brais LK, Daskalova A, Heafield R et al. 2013 Prognostic significance of mTOR pathway component expression in neuroendocrine tumors. Journal of Clinical Oncology 31 3418-3425. (doi:10.1200/JCO.2012.46.6946)

Righi L, Volante M, Rapa I, Tavaglione V, Inzani F, Pelosi G \& Papotti M 2010 Mammalian target of rapamycin signaling activation patterns in neuroendocrinetumors of the lung. Endocrine-Related Cancer 17 977-987. (doi:10.1677/ERC-10-0157)

Roldo C, Missiaglia E, Hagan JP, Falconi M, Capelli P, Bersani S, Calin GA, Volinia S, Liu CG, Scarpa A et al. 2006 MicroRNA expression abnormalities in pancreatic endocrine and acinar tumors are associated with distinctive pathologic features and clinical behavior. Journal of Clinical Oncology 24 4677-4684. (doi:10.1200/JCO.2005.05.5194)

Ruza A, Griniak K, Phillip L, Felder S, Pape FU \& Manfred D 2014 Immunohistochemical analysis of mTOR pathway expression in gastric neuroendocrine tumors. Journal of Clinical \& Experimental Pathology 4 173. (doi:10.4172/2161-0681.1000173)

Sahnane N, Furlan D, Monti M, Romualdi C, Vanoli A, Vicari E, Solcia E, Capella C, Sessa F \& La Rosa S 2015 Microsatellite unstable gastrointestinal neuroendocrine carcinomas: a new clinicopathologic entity. Endocrine-Related Cancer 22 35-45. (doi:10.1530/ERC-14-0410)

Sasaki H, Okuda K, Kawano O, Yukiue H, Yano M \& Fujii Y 2008 Fibroblast growth factor receptor 4 mutation and polymorphism in Japanese lung cancer. Oncology Reports 20 1125-1130. (doi:10.3892/ or_00000119)

Serra S, Zheng L, Hassan M, Phan AT, Woodhouse LJ, Yao JC, Ezzat S \& Asa SL 2012 The FGFR4-G388R single-nucleotide polymorphism alters pancreatic neuroendocrine tumor progression and response to mTOR inhibition therapy. Cancer Research 72 5683-5691. (doi:10.1158/00085472.CAN-12-2102)

Shi Y, Gera J, Hu L, Hsu JH, Bookstein R, Li W \& Lichtenstein A 2002 Enhanced sensitivity of multiple myeloma cells containing PTEN mutations to CCI-779. Cancer Research 62 5027-5034.

Shida T, Kishimoto T, Furuya M, Nikaido T, Koda K, Takano S, Kimura F, Shimizu H, Yoshidome H, Ohtsuka M et al. 2010 Expression of an activated mammalian target of rapamycin (mTOR) in gastroenteropancreatic neuroendocrine tumors. Cancer Chemotherapy and Pharmacology 65 889-893. (doi:10.1007/s00280-009-1094-6)

Shields AF, Grierson JR, Dohmen BM, Machulla HJ, Stayanoff JC, LawhornCrews JM, Obradovich JE, Muzik O \& Mangner TJ 1998 Imaging proliferation in vivo with [F-18]FLT and positron emission tomography. Nature Medicine 4 1334-1336. (doi:10.1038/3337)

Spada F, Fazio N, Capurso G, Panzuto F, Rinzivillo M, Pisa E, Pilozzi E, Radice D, Di Rocco R, Galdy S et al. 2014 PI3K-AKT-mTOR pathway disregulation and its correlation with clinical outcome in patients with advanced neuroendocrine tumors treated with everolimus. NANETS Meeting Abstracts. Pancreas 43493.

Steelman LS, Navolanic PM, Sokolosky ML, Taylor JR, Lehmann BD, Chappell WH, Abrams SL, Wong EW, Stadelman KM, Terrian DM et al. 2008 Suppression of PTEN function increases breast cancer chemotherapeutic drug resistance while conferring sensitivity to mTOR inhibitors. Oncogene 27 4086-4095. (doi:10.1038/onc.2008.49)

Therasse P, Arbuck SG, Eisenhauer EA, Wanders J, Kaplan RS, Rubinstein L, Verweij J, Van Glabbeke M, van Oosterom AT, Christian MC et al. 2000 New guidelines to evaluate the response to treatment in solid tumors. European Organization for Research and Treatment of Cancer, National Cancer Institute of the United States, National Cancer Institute of Canada. Journal of National Cancer Institute 92 205-216. (doi:10.1093/jnci/92.3.205)

Therasse P, Eisenhauer EA \& Verweij J 2006 RECIST revisited: a review of validation studies on tumour assessment. European Journal of Cancer $\mathbf{4 2}$ 1031-1039. (doi:10.1016/j.ejca.2006.01.026)

Thussbas C, Nahrig J, Streit S, Bange J, Kriner M, Kates R, Ulm K, Kiechle M, Hoefler H, Ullrich A et al. 2006 FGFR4 Arg388 allele is associated with resistance to adjuvant therapy in primary breast cancer. Journal of Clinical Oncology 24 3747-3755. (doi:10.1200/JCO.2005. 04.8587) 
Vinik AI, Silva MP, Woltering EA, Woltering G, Go VL, Warner R \& Caplin M 2009 Biochemical testing for neuroendocrine tumors. Pancreas $\mathbf{3 8}$ 876-889. (doi:10.1097/MPA.0b013e3181bc0e77)

Wander SA, Hennessy BT \& Slingerland JM 2011 Next-generation mTOR inhibitors in clinical oncology: how pathway complexity informs therapeutic strategy. Journal of Clinical Investigation 121 1231-1241. (doi:10.1172/JCI44145)

Wang J, Stockton DW \& Ittmann M 2004 The fibroblast growth factor receptor-4 Arg388 allele is associated with prostate cancer initiation and progression. Clinical Cancer Research 10 6169-6178. (doi:10.1158/ 1078-0432.CCR-04-0408)

Weber WA \& Wieder H 2006 Monitoring chemotherapy and radiotherapy of solid tumors. European Journal of Nuclear Medicine and Molecular Imaging 33 (Suppl 1) 27-37. (doi:10.1007/s00259-006-0133-3)

von Wichert G, Jehle PM, Hoeflich A, Koschnick S, Dralle H, Wolf E, Wiedenmann B, Boehm BO, Adler G \& Seufferlein T 2000 Insulin like growth factor-I is an autocrine regulator of chromogranin A secretion and growth in human neuroendocrine tumor cells. Cancer Research 60 4573-4581.

Wullschleger S, Loewith R \& Hall MN 2006 TOR signaling in growth and metabolism. Cell 124 471-484. (doi:10.1016/j.cell.2006.01.016)

Yao JC, Hassan M, Phan A, Dagohoy C, Leary C, Mares JE, Abdalla EK, Fleming JB, Vauthey JN, Rashid A et al. 2008a One hundred years after "carcinoid": epidemiology of and prognostic factors for neuroendocrine tumors in 35,825 cases in the United States. Journal of Clinical Oncology 26 3063-3072. (doi:10.1200/JCO.2007.15.4377)

Yao JC, Phan AT, Chang DZ, Wolff RA, Hess K, Gupta S, Jacobs C, Mares JE, Landgraf AN, Rashid A et al. 2008 b Efficacy of RAD001 (everolimus) and octreotide LAR in advanced low- to intermediate-grade neuroendocrine tumors: results of a phase II study. Journal of Clinical Oncology 26 4311-4318. (doi:10.1200/JCO.2008.16.7858)

Yao JC, Lombard-Bohas C, Baudin E, Kvols LK, Rougier P, Ruszniewski P, Hoosen S, St. Peter J, Haas T, Lebwohl D et al. 2010 Daily oral everolimus activity in patients with metastatic pancreatic neuroendocrine tumors after failure of cytotoxic chemotherapy: a phase II trial. Journal of Clinical Oncology 28 69-76. (doi:10.1200/JCO.2009.24.2669)
Yao JC, Shah MH, Ito T, Bohas CL, Wolin EM, Van Cutsem E, Hobday TJ, Okusaka T, Capdevila J, de Vries EG et al. 2011a RAD001 in Advanced Neuroendocrine Tumors, Third Trial (RADIANT-3) Study Group. Everolimus for advanced pancreatic tumors. New England Journal of Medicine 364 514-523. (doi:10.1056/NEJMoa1009290)

Yao JC, Pavel M, Phan AT, Kulke MH, Hoosen S, St Peter J, Cherfi A \& Öberg KE $2011 b$ Chromogranin A and neuron-specific enolase as prognostic markers in patients with advanced pNET treated with everolimus. Journal of Clinical Endocrinology \& Metabolism 96 3741-3749. (doi:10.1210/jc.2011-0666)

Yao JC, Fazio N, Singh S, Buzzoni R, Carnaghi C, Wolin E, Tomasek J, Raderer M, Lahner H, Voi M, et al. 2015 Safety and efficacy of everolimus in advanced nonfunctional neuroendocrine tumors (NET) of lung or gastrointestinal (GI) origin: findings of the randomized, placebo-controlled, double-blind, multicenter, phase 3 RADIANT-4 study. In 2015 NANETS Neuroendocrine Tumor Symposium Abstracts, abstract C51. Vancouver, WA, USA: NANETS. (available at: https:// www.nanets.net/nanets_cd/2015/pdfs/C51.pdf)

Yuan F, Shi M, Ji J, Shi H, Zhou C, Yu Y, Liu B, Zhu Z \& Zhang J 2014 KRAS and DAXX/ATRX gene mutations are correlated with the clinicopathological features, advanced diseases, and poor prognosis in Chinese patients with pancreatic neuroendocrine tumors. International Journal of Biological Sciences 10 957-965. (doi:10.7150/ijbs.9773)

Zhou CF, Ji J, Yuan F, Shi M, Zhang J, Liu BY \& Zhu ZG 2011 mTOR activation in well differentiated pancreatic neuroendocrine tumors: a retrospective study on 34 cases. Hepatogastroenterology 58 2140-2143. (doi:10.5754/hge11212)

Zitzmann K, De Toni EN, Brand S, Göke B, Meinecke J, Spöttl G, Meyer HH \& Auernhammer CJ 2007 The novel mTOR inhibitor RAD001 (everolimus) induces antiproliferative effects in human pancreatic neuroendocrine tumor cells. Neuroendocrinology 85 54-60. (doi:10.1159/000100057)

Zitzmann K, Vlotides G, Brand S, Lahm H, Spottl G, Goke B \& Auernhammer CJ 2012 Perifosine-mediated Akt inhibition in neuroendocrine tumor cells: role of specific Akt isoforms. Endocrine-Related Cancer 19 423-434. (doi:10.1530/ERC-12-0074)

Received 9 December 2015

Accepted 14 December 2015

Made available online as an Accepted Preprint

14 December 2015
(C) 2016 Society for Endocrinology Printed in Great Britain 